\title{
Effect of Fungicide Applications on Monilinia fructicola Population Diversity and Transposon Movement
}

\author{
Madeline E. Dowling, Patricia K. Bryson, Harriet G. Boatwright, Jennifer R. Wilson, Zhen Fan, Sydney E. Everhart, \\ Phillip M. Brannen, and Guido Schnabel
}

First, second, third, fourth, fifth, and eighth authors: Department of Agricultural and Environmental Sciences, Clemson University, Clemson, SC 29634; sixth author: Department of Plant Pathology, University of Nebraska, Lincoln 68583; and seventh author: Plant Pathology Department, University of Georgia, Athens 30602.

Accepted for publication 21 July 2016.

\begin{abstract}
Dowling, M. E., Bryson, P. K., Boatwright, H. G., Wilson, J. R., Fan, Z., Everhart, S. E., Brannen, P. M., and Schnabel, G. 2016. Effect of fungicide applications on Monilinia fructicola population diversity and transposon movement. Phytopathology 106:1504-1512.

In this study, we investigated whether fungicide-induced mutagenesis previously reported in Monilinia fructicola could accelerate genetic changes in field populations. Azoxystrobin and propiconazole were applied to nectarine trees at weekly intervals for approximately 3 months between bloom and harvest in both 2013 and 2014. Fungicides were applied at half-label rate to allow recovery of isolates and to increase chances of sublethal dose exposure. One block was left unsprayed as a control. In total, 608 single-spore isolates were obtained from blighted blossoms, cankers, and fruit to investigate phenotypic (fungicide resistance) and genotypic (simple-sequence repeat [SSR] loci and gene region) changes.

In both years, populations from fungicide-treated and untreated fruit were not statistically different in haploid gene diversity $(P=0.775$ for 2013 and $P=0.938$ for 2014), allele number $(P=0.876$ for 2013 and $P=$ 0.406 for 2014), and effective allele number $(P=0.861$ for 2013 and $P=0.814$ for 2014). Isolates from blossoms and corresponding cankers of fungicide treatments revealed no changes in SSR analysis or evidence for induced $\mathrm{Mftcl}$ transposon translocation. No indirect evidence for increased genetic diversity in the form of emergence of reduced sensitivity to azoxystrobin, propiconazole, iprodione, and cyprodinil was detected. High levels of population diversity in all treatments provided evidence for sexual recombination of this pathogen in the field, despite apparent absence of apothecia in the orchard. Our results indicate that fungicide-induced, genetic changes may not occur or not occur as readily in field populations as they do under continuous exposure to sublethal doses in vitro.
\end{abstract}

Monilinia fructicola G. Winter (Honey) is a causal agent of brown rot, one of the most damaging diseases affecting stone fruit production worldwide (Ames 2012; Ogawa et al. 1995; Roberts and Dunegan 1932). M. fructicola overwinters in fruit mummies and twig cankers (Holb 2008; Honey 1936; Sutton and Clayton 1972; Zhong et al. 2008). In spring, apothecia develop from fruit mummies and produce ascospores, which can infect blossoms (Byrde and Willetts 1977; Landgraf and Zehr 1982). Fungal mycelium may subsequently colonize twig tissue (Sutton and Clayton 1972) and develop into cankers capable of girdling twigs and decreasing the fruitbearing area of the tree (Holb 2008). Inoculum produced from blighted blossoms and cankers spreads to green and maturing fruit, causing preharvest and postharvest fruit rot that can result in 100\% disease losses without fungicide intervention (Ogawa et al. 1995).

Quinone outside inhibitor (QoI) fungicides such as azoxystrobin and demethylation inhibitor (DMI) fungicides such as propiconazole are commonly recommended for brown rot control (Ames 2012). QoI fungicides suppress ATP synthesis by inhibition of electron transfer at the quinone oxidation (Qo) site in the cytochrome $b c l$ complex, and DMI fungicides inhibit sterol biosynthesis essential to fungal cell membrane fluidity (Bartlett et al. 2002; Gisi et al. 2000). Reduced sensitivity to azoxystrobin and resistance to propiconazole have been reported in production areas in the southeastern United States (Horton et al. 2014; Luo et al. 2008, 2010). Disease management practices recommended to reduce risk of fungicide resistance are to avoid consecutive applications of single-site fungicides that

Corresponding author: G. Schnabel; E-mail address: schnabe@clemson.edu have the same mode of action, to decrease selection pressure for resistance, and to use the maximum label rate (Beckerman 2008). These recommendations will not eliminate sublethal exposure that may result from incomplete plant canopy penetration or coverage or dilution of fungicide concentrations in plant tissue.

Sublethal exposure of the target pathogen to fungicides may cause stress, indirectly resulting in DNA mutation. For example, respiration-inhibitor fungicides may induce generation of reactive oxygen species (ROS) such as superoxide radicals and hydrogen peroxide (Kaneko and Ishii 2009). This was observed when QoI fungicide SSF126 was applied to control the rice blast fungus Magnaporthe grisea (Bartlett et al. 2002; Mizutani 1996). Multiple studies have shown that oxidative stress caused by ROS can induce transposon movement, simple-sequence repeat (SSR) instability, DNA double-strand breaks, and RNA splicing inaccuracies in fungi and bacteria (Chadha and Sharma 2014; Evans and Cooke 2004; Georg et al. 2009). It is still unknown whether such fungicideinduced oxidative stress increases risk of fungicide resistance.

In a previous laboratory study, we showed that exposure of Monilinia fructicola to sublethal levels of azoxystrobin in vitro resulted in mutation at noncoding SSR loci and $\mathrm{Mftcl}$ transposon movement (Chen et al. 2015; Schnabel et al. 2014). It is not known whether such DNA damage occurs from field application of fungicides. This information would be important for determining risk of resistance development (Grimmer et al. 2015) and determining whether fungicide-induced mutagenesis should be a management concern for $M$. fructicola. The goal of this study was to determine whether consecutive application of azoxystrobin at half-label rates would induce mutagenesis in $M$. fructicola. We used propiconazole as a fungicide control because its mode of action is not related to ROS production and it did not cause mutagenesis in the in vitro 
study performed by Chen et al. (2015). In our experimental design, we used three complementary methods to compare fungicide treated and untreated populations. We compared genetic diversity at the population level, genetic profiles of individual isolates, and fungicide resistance phenotypes within populations. We hypothesized that sublethal fungicide-induced mutagenesis would generate higher diversity in the azoxystrobin-treated population compared with the propiconazole-treated population. This hypothesis was also investigated at the single-isolate level, which further controlled variables encountered in the population-level study such as the unknown extent of genetic diversity within the population and potential gene flow between populations. Finally, resistance profiling allowed us to examine, on the phenotypic level, whether a population shift and potential mutagenesis resulted from half-label rate fungicide exposure. Results of this study provide the first insights into the potential for fungicide-induced mutagenesis under field conditions.

\section{MATERIALS AND METHODS}

Field trials and fungicide applications. All isolates for SSR analysis were collected prior to fungicide treatment from a block of 'June Princess' nectarine trees in Clemson University's Musser Fruit Research Farm, Seneca, SC and 'O'Henry' peach in the University of Georgia (UGA) Horticulture Research Farm, Watkinsville. Orchard plots used for this experiment were established in 2003, with fungicides, herbicides, and pesticides applied according to standard commercial protocol prior to the experiment (Horton et al. 2014). It was previously determined that the natural $M$. fructicola population present prior to this experiment was sensitive to QoI and DMI fungicides, based on annual monitoring data (data not shown). The experimental design used in each orchard is shown in Figure 1. There were eight to nine trees in each row, and collections were made from five of these trees in each of the treatment rows. The five trees used in the experiment were rerandomized each year.

Fungicide applications were made using an airblast sprayer with azoxystrobin (Abound Flowable, 22.9\% azoxystrobin; Syngenta Crop Protection, Greensboro, NC) applied at $420 \mathrm{~g} / \mathrm{ha}$ and propiconazole (Tilt, $41.8 \%$ propiconazole; Syngenta Crop Protection) applied at 141 $\mathrm{g} / \mathrm{ha}$, both in water final spray volume of 938 liters/ha. Rates represented half-label rate to increase chances of sublethal dose exposure, and to ensure sufficient pathogen survival for resampling later in the season. In total, 12 and 10 fungicide applications were made at each location in 2013 and 2014, respectively. Each fungicidetreated block was buffered with nontreated trees and rows. No fungicide was applied prior to collection of blossom blight isolates, referred to as pretreatment populations.

Field collection and single-spore isolations. In both 2013 and 2014, isolates for SSR analysis were randomly collected from blossoms after petal fall (March to April) and from mature fruit approximately 12 weeks later. Only blossoms and fruit exhibiting obvious conidial tufts were used. Additional isolates were collected from blossoms in spring and corresponding cankers in summer for transposon translocation and SSR analysis. Two weather-proof tags, printed with the isolate name, were attached to the branch proximal and distal to the blossom blight, which enabled sampling of the corresponding canker later in the season. Selection criteria for blighted blossoms required that they be distant from other infected blossoms on the same branch, located on otherwise healthy branches, distributed throughout the canopy, and attached to branches with a diameter $\geq 1 \mathrm{~cm}$. Nearby healthy blossoms were removed to prevent the possibility of label confusion. Five trees were selected from each experimental row, and 20 isolates were collected within each tree canopy. Spores were collected from symptomatic flowers by gently swirling the cotton tip of a sterile, individually wrapped swab in newly formed spore masses and then replacing the swab in the wrapping (Thermo Fisher Scientific, Waltham, MA). Swabs were placed in freezer bags containing solid desiccant and refrigerated at $4^{\circ} \mathrm{C}$ until further use. For single-spore isolations, swabs were tapped over water agar plates and then incubated in the dark at $22^{\circ} \mathrm{C}$ for $16 \mathrm{~h}$. Using a microscope, individual germinating conidia were aseptically transferred with a scalpel to potato dextrose agar (PDA) and grown for 5 to 7 days. Mycelium was then harvested for DNA extraction and permanent storage.

Twig cankers were collected after season-long fungicide applications from the Musser Fruit Research Farm on 1 July 2014 and from the UGA Horticulture Research Farm on 10 July 2014. Branch segments approximately $1 \mathrm{~cm}$ in diameter containing a single canker were cut to 4 to $5 \mathrm{~cm}$ in length. Twigs were surface sterilized in $10 \%$ bleach solution for $1 \mathrm{~min}$, rinsed for $1 \mathrm{~min}$ in ultrapure filtered water, then dried in a laminar flow hood on paper towels and placed in labeled petri dishes. Each dish contained filter paper $9.0 \mathrm{~cm}$ in diameter (number 410; VWR, Radnor, PA), saturated with ultrapure
A

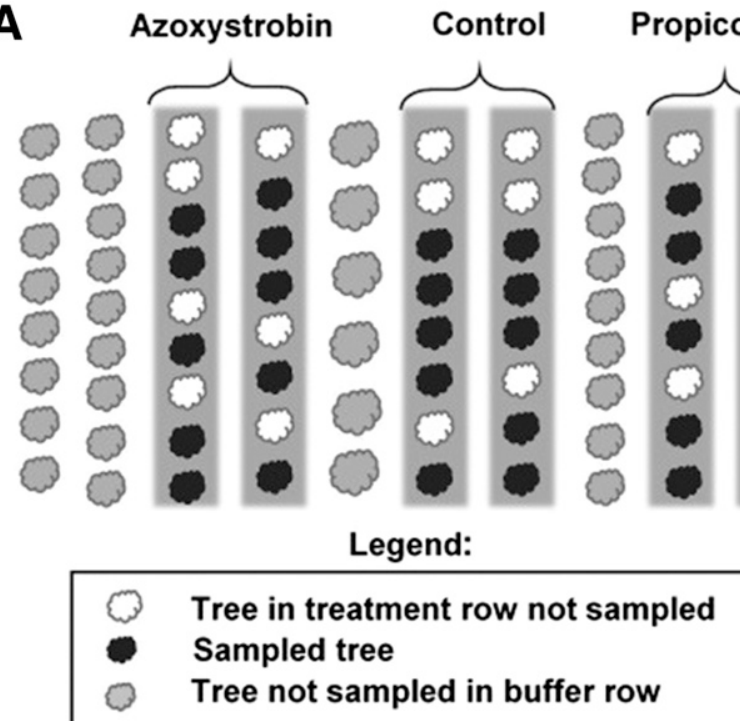

B Control Azoxystrobin

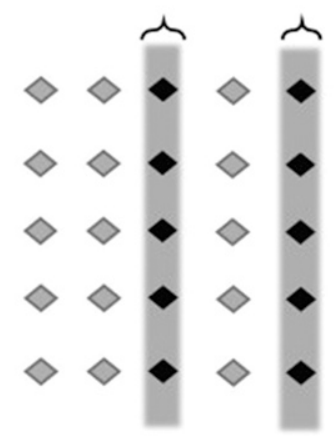

Legend:

10 sampled

10 trees not sampled in buffer

Fig. 1. Schematic of field experiment at A, Musser Fruit Research Farm, Seneca, SC and B, University of Georgia (UGA) Horticulture Research Farm, Watkinsville, GA. At the Musser Fruit Research Farm, 20 isolates were collected from each of the 10 trees per treatment shaded black in the schematic above. At the UGA Horticulture Research Farm, 150 isolates were collected at random from trees of each treatment. 
water to create a moist chamber. Petri dish lids were left closed for 3 days and then barely propped open to stimulate sporulation. Petri dishes containing cankers were removed after sporulation to prevent cross-contamination. After 1 to 5 weeks, spores emerged and were recovered from approximately $45 \%$ of cankers. Spores were collected using sterile swabs, and wrapped swabs were stored in a plastic bag with desiccant. Single-spore isolations were performed as described above. Isolates from blossoms and corresponding cankers are referred to as "matching pairs" if nucleotide sequences of the multidrug resistance regulator ( $m r r l)$, dihydrofolate reductase $(D H F R)$, and cytochrome P450 (as-yet-undescribed and MfCYPO1) genes were identical.

Disease incidence and fungicide sensitivity. Approximately 1 week prior to sampling isolates in spring and summer 2014 , blossom blight and fruit rot disease incidence were determined. For blossom blight, 10 1-year-old branches approximately the same length were chosen from each of 10 trees, and total number of both asymptomatic and symptomatic blossoms counted. For fruit rot incidence, 100 randomly selected fruit were examined on each tree for all 10 trees in each treatment and the number of fruit with brown rot symptoms and signs was determined. Disease incidence was not estimated in 2013.

In vitro fungicide sensitivity was determined for 50 isolates from each field treatment to commercial formulations of azoxystrobin (Abound Flowable, 22.9\% azoxystrobin; Syngenta Crop Protection), propiconazole (Tilt, $25.1 \%$ propiconazole; Syngenta Crop Protection), cyprodinil (Vanguard, 75\% cyprodinil; Syngenta Crop Protection), and iprodione (Rovral, iprodione 41.6\%; Bayer Crop Science, Research Triangle Park, NC). All fungicide amendments were added to PDA media, except for cyprodinil, which was added to Czapek-Dox agar. Fungicides were added to media after cooling to between 37 and $42^{\circ} \mathrm{C}$ in a water bath to prevent fungicide decomposition. Sensitivity was estimated from relative growth at discriminatory doses for each fungicide: $0.3,0.01,0.05$, and $0.3 \mu \mathrm{g} / \mathrm{ml}$ for azoxystrobin, propiconazole, cyprodinil, and iprodione, respectively. Multiple concentrations were tested in preliminary studies but the ones indicated above resulted in a normal distribution of isolate frequencies (data not shown). Salicylhydroxamic acid (SHAM) was added at a final concentration of $75 \mu \mathrm{g} / \mathrm{ml}$ to azoxystrobin-amended media to inhibit alternative oxidase activity of $M$. fructicola. Colony diameter was measured after 3 to 4 days of growth in the dark at $22^{\circ} \mathrm{C}$. Relative growth was calculated as the ratio of colony diameter on amended to unamended media or, in the case of azoxystrobin, to SHAM-amended media. Though cyprodinil and iprodione were not used in the field experiment, these fungicides were important to consider because mutagenesis is likely random and would not necessarily result in resistance only to the fungicide being applied but might result in resistance to other chemical classes of fungicides as well.

DNA extraction. DNA was purified using "the quick and safe method" (Chi et al. 2009) according to all recommendations, except that sample DNA was washed with chilled ethanol and centrifuged at 13,400 relative centrifugal force (rcf) for $3 \mathrm{~min}$. Ethanol supernatant was discarded and residual ethanol evaporated in a laminar flow hood until the pellet dried. Tris-EDTA (TE) buffer $(50 \mu \mathrm{l})$ was added to DNA, and tubes were placed in a water bath at $45^{\circ} \mathrm{C}$ for several hours to ensure that the DNA dissolved. TE buffer was made by mixing a solution of $10 \mathrm{mM}$ Tris, $\mathrm{pH} 8.0$ and a solution of $0.1 \mathrm{mM}$ EDTA, pH 8.0. DNA was stored at $-20^{\circ} \mathrm{C}$.

For Southern blot analysis, each isolate was grown in two $250-\mathrm{ml}$ Erlenmeyer flasks containing $150 \mathrm{ml}$ of potato dextrose broth. After 1 to 2 weeks, mycelium was harvested and vacuum filtered using 9-cm P8 filter paper (Thermo Fisher Scientific). Mycelium was rinsed with distilled water and vacuum filtered dry. Dried mycelium $(1 \mathrm{~g})$ for each isolate was weighed, placed into a labeled petri dish sealed with Parafilm, and stored at $-80^{\circ} \mathrm{C}$. DNA was extracted using a modified cetyltrimethylammonium bromide (CTAB) protocol. Stored mycelium was ground into a fine powder using a liquid-nitrogen-cooled mortar and pestle. Frozen, pulverized tissue was added to $2.8 \mathrm{ml}$ of CTAB extraction solution (2\% CTAB powder, $10 \mathrm{mM} 1 \mathrm{M}$ Tris $\mathrm{HCl}$ [pH 8.0;1.4 M NaCl]) preheated to $65^{\circ} \mathrm{C}$ in $15-\mathrm{ml}$ Corning tubes. Resulting homogenate was vortexed and incubated at $65^{\circ} \mathrm{C}$. After $30 \mathrm{~min}$, the homogenate was added to Phase Lock Gel (PLG) tubes and centrifuged at $1,510 \mathrm{rcf}$ at room temperature. Chloroform $(2.8 \mathrm{ml})$ was added and mixed into the homogenate by inversion, then centrifuged at 1,510 rcf for $5 \mathrm{~min}$. Clear supernatant (avoiding interface) was then transferred to a new $15-\mathrm{ml}$ tube and $8 \mathrm{ml}$ of precipitation solution was added (1\% CTAB powder, $50 \mathrm{mM} 1 \mathrm{M}$ Tris $\mathrm{HCl}$ [pH 8.0], and $10 \mathrm{mM}$ $0.5 \mathrm{M}$ EDTA [pH 8.0]). Tubes were stored in the $-20^{\circ} \mathrm{C}$ freezer overnight and thawed the next day before use. After thawing, the tubes were centrifuged at 4,180 $\mathrm{rcf}$ for $30 \mathrm{~min}$ and the supernatant was removed, keeping the pellet. To dissolve the pellet, $4 \mathrm{ml}$ of $1 \mathrm{M} \mathrm{NaCl}$ solution was added to it. This homogenate was then transferred to a spun-down PLG tube, mixed well by inversion, and centrifuged at $1,510 \mathrm{rcf}$ for $5 \mathrm{~min}$. Supernatant was transferred to a new $15-\mathrm{ml}$ Corning tube and $7 \mathrm{ml}$ of prechilled $100 \%$ ethanol added. The tube was stored at $-20^{\circ} \mathrm{C}$ overnight to allow DNA precipitation. Later, the tube was centrifuged at 4,180 rcf and then ethanol was decanted, which was repeated twice. The pellet was dried in the hood for $3 \mathrm{~h}$ or until clear. In total, 40 to $100 \mu \mathrm{l}$ of ultrapure water was added until the DNA pellet dissolved, at which point it was stored at $-20^{\circ} \mathrm{C}$.

SSR genotyping. PCR was performed using the SSR primers SED, SEF, SEI, SEL, SEN, SEP, and SEQ, as described previously (Everhart et al. 2012). All primers were pig-tailed with GTTT to reduce stutter peak formation and a CAG sequence was added to one primer in order to generate the comparable fragment sizes reported previously (Everhart et. al. 2012). Fluorophore FAM directly labeled one primer for each locus, which resulted in better amplification than indirect CAG-fluorophore labeling. Thermal cycler conditions used were an initial cycle of $95^{\circ} \mathrm{C}$ for $2 \mathrm{~min}$ and $30 \mathrm{~s}$, followed by a touchdown cycle repeated 20 times of $95^{\circ} \mathrm{C}$ for $20 \mathrm{~s}, 60^{\circ} \mathrm{C}$ for $20 \mathrm{~s}$ with temperature decreasing by $0.5^{\circ} \mathrm{C}$ every cycle, and $72^{\circ} \mathrm{C}$ for $30 \mathrm{~s}$. The third cycle of $95^{\circ} \mathrm{C}$ for $20 \mathrm{~s}, 50^{\circ} \mathrm{C}$ for $20 \mathrm{~s}$, and $72^{\circ} \mathrm{C}$ for $30 \mathrm{~s}$ was repeated 15 times, followed by a final extension at $72^{\circ} \mathrm{C}$ for $5 \mathrm{~min}$.

Fragment analysis was performed at Arizona State University. Fragment sizes were called using Genemapper 4.0 (Life Technologies, Carlsbad, CA) software. Genetic data were analyzed in GenAlex 6.5 (Peakall and Smouse 2006) to calculate unbiased haploid genetic diversity that gives the likelihood that two individuals in a population will differ in alleles; number of multilocus genotypes (MLG), which indicates how many clones are present in a population; and number of private alleles, which gives the number of alleles found in only one population. Index of association $\left(\mathrm{I}_{\mathrm{A}}\right)$ was calculated using the $\mathrm{R}$ package poppr (Kamvar et al. 2014), which is an estimate of linkage disequilibrium and used to infer modes of reproduction. An analysis of molecular variance (AMOVA) was also performed in GenAlex to detect whether there was a significant difference between populations. The number of MLG and number of private alleles were determined before clone correction, while the unbiased haploid genetic diversity, AMOVA, and $\mathrm{I}_{\mathrm{A}}$ calculations were performed on clone-corrected data. Numbers of private alleles and MLG were determined independently for treatment populations by year and by blossom or fruit isolate source. The $\mathrm{R}$ package poppr was used to calculate a genotype accumulation curve and used to ensure that genotypes were sufficiently resolved, as demonstrated when the slope of the line tangential to the curve approaches 0. Distribution of MLG resolved in the population was estimated from each possible combination loci by randomly sampling 1 to $n-1$ loci (where $n$ is the total number of loci) and repeated 1,000 times without replacement in order to generate a distribution for each number of loci sampled. JMP 11.0 (SAS Institute, Inc., Cary, NC) was used to compare means, first using analysis of variance and then, if differences were detected, a Tukey's highly significant difference posthoc test was used to detect populations that were different, with significance determined at $\alpha=0.05$. 
Identification of matching pairs from cankers and blossoms. Isolates from blossoms and corresponding cankers were used for SSR analysis to detect potential genetic changes at single infection sites. The mrrl, DHFR, and MfCYPOl loci were sequenced for canker and blossom pairs using a previously described method (Dowling 2015). The sequences of these genes are polymorphic, capable of differentiating isolates of $M$. fructicola, and provide greater confidence that matching isolates are truly identical because mutation rates are known to be considerably lower in these regions as compared with SSR loci. Sequencing was performed by CORE laboratories at Arizona State University. Sequences were assembled and compared using DNAstar software (DNAstar Inc., Madison, WI).

Southern blot analysis of $\mathbf{M f t c 1}$ in matching pairs. In all, 17 matching pairs ( 34 isolates) $(7,6$, and 4 pairs from azoxystrobin, propiconazole, and control treatment populations, respectively) were assayed for their Mftcl Southern blot profiles. Transposable element $M f t c 1$ is 1,504 bp in size (Luo et al. 2008). The only other known transposon in M. fructicola, Mona (Luo and Schnabel 2008), did not provide a sufficient signal in our experiments, perhaps because of its short length ( $65 \mathrm{bp}$; data not shown). Prior to Southern blot analysis, approximately $50 \mu \mathrm{g}$ of DNA from each isolate was digested using the enzyme Bam H1-HF (New England Biolabs, Ipswich, MA). Digestion reactions contained DNA, $4 \mu$ l each of Cut Smart buffer and enzyme, and water added to $40 \mu$ l. The reaction was performed overnight at $37^{\circ} \mathrm{C}$. Digested DNA was separated on a $0.8 \%$ agarose gel at a constant voltage of $25 \mathrm{~V}$ overnight. Membrane transfer solutions were made according to the protocol of Amersham Hybond N+ (GE Healthcare 2006b). The gel was gently agitated while exposed to depurination solution for $10 \mathrm{~min}$, then denaturation solution for $30 \mathrm{~min}$, and, finally, neutralization solution for $30 \mathrm{~min}$, with neutralization solution changed after $15 \mathrm{~min}$. After each step, the gel was rinsed with distilled water. Membrane transfer was performed according to the Amersham Hybond N+ protocol (GE Healthcare 2006c). The $M f t c l$ probe was amplified using the primer pairs mtcf1 5'-GGGATATTAACCAATCACAACGT-3' and mtcr2 5'CGATTGGACAGATAAGCAATGG- $3^{\prime}$ from the isolate NY9C, known to contain the $M f t c l$ element, and the product was purified by gel extraction (Zymo Research, Irvine, CA) (Chen et al. 2015). Hybridization and signal detection were performed according to manufacturer recommendation for Amersham Gene Images AlkPhos Direct Labeling and Detection System with CDP-star (GE Healthcare 2006a).

\section{RESULTS}

Disease incidence and fungicide sensitivity. Disease incidence was determined for the Musser Farm before and after fungicide applications in 2014. Pretreatment blossom blight incidence in azoxystrobin, propiconazole, and control blocks was 29.4, 23.3, and $23.9 \%$, respectively, and was not significantly different $(P=$ $0.390)$. Fruit rot incidence for azoxystrobin, control, and propiconazole treatment blocks was 5.3, 38.3, and 2.7\%, respectively. No significant difference in fruit rot incidence was found between azoxystrobin and propiconazole treatments $(P=0.627)$ but fruit rot incidence in these treatments was significantly lower than in the untreated control $(P=0.0001)$. These data indicated that disease pressure was uniformly distributed prior to fungicide applications among treatments and disease control was similar for both fungicide treatments.

The in vitro fungicide sensitivity to azoxystrobin and propiconazole was not different among isolates from each treatment in 2013 $(P=0.385)$ and $2014(P=0.253)$ (Fig. 2$)$, though one outlier isolate exhibited resistance to propiconazole in 2013. Sensitivity of isolates to iprodione and cyprodinil was additionally determined in 2013 but no significant difference in sensitivity with respect to treatment was observed to iprodione $(P=0.181)$ or cyprodinil $(P=0.239$; sensitivity data not shown).
Genetic and genotypic variation. Due to an insufficient number of samples present at the UGA Horticulture Research Farm, genetic diversity analysis was performed only on samples collected at the Musser Farm in 2013 and 2014. At the Musser Farm, 7 isolates were obtained from both blossoms and fruit of five trees for a total of 35 blossom and 35 fruit isolates from each of the three treatments in 2013 and 2014 to determine population diversity differences (total of 420 isolates for both years). Of the 420 isolates collected, 388 were recovered from swabs and genotyped. Among all isolates genotyped, all seven SSR loci were polymorphic, with an average of 5.7 alleles at each locus and 3.3 effective alleles at each locus, which is the number of alleles weighted by frequency. An average of 97.9 and $94.4 \%$ of isolates from blossoms and fruit, respectively, were genetically unique (not clonal genotypes). To determine whether the SSR loci were powerful enough to differentiate isolates, a genotype accumulation curve was generated using pooled data from all 388 isolates (Fig. 3). This dataset contained 274 MLG, where the number of MLG increased in a sigmoidal curve, beginning to plateau at 6 loci.

The number of private alleles was determined to measure the number of alleles not found in any other population. Private alleles in a treatment population ranged from 2 to 10 (Table 1). The number of private alleles was variable between treatment populations in both years, with no population showing a consistently larger number of private alleles than any other. Similarly, percentage of unique MLG within each treatment population and pretreatment population was determined for each isolate source and collection year. Values ranged from 85 to $100 \%$ and indicated little variation in number of unique MLG among treatment population, isolate source, and collection year. The number of private alleles and MLG values were too few to compare statistically; therefore, significant difference in haploid gene diversity was used as a proxy (Table 1).

Haploid genetic diversity is a measure of allelic variation and was used to test whether global diversity increased in response to fungicide treatment. All haploid genetic diversity values were calculated from clone-corrected data. No difference was observed in haploid genetic diversities of pretreatment blossom isolates collected from each treatment block in either collection year (2013, $P=0.333$ and 2014, $P=0.451$ ). Similarly, no difference was observed for populations of fruit isolates obtained from control, azoxystrobin, and propiconazole treatments in $2013(P=0.775)$ or $2014(P=0.938)$.

The average number of alleles per locus was determined to indicate the potential for diversity in the population. There was no significant difference in the number of alleles among treatment population, collection year, or isolate source. With regard to isolates from blossoms, there were no differences among treatment populations in $2013(P=0.332)$ and $2014(P=0.426)$. Likewise, no significant differences in number of alleles among treatment populations from fruit were detected in $2013(P=0.876)$ or 2014 $(P=0.406)$. Complementary to this, the effective number of alleles was determined to provide an overall representation of population evenness by weighting each allele based on its frequency in the population. For both blossom and fruit isolates, there was no significant difference in the number of effective alleles among all pretreatment populations in $2013(P=0.552$ for blossoms and $P=$ 0.876 for fruit) or 2014 ( $P=0.421$ for blossoms and $P=0.814$ for fruit).

AMOVA calculated pairwise $\Phi_{\mathrm{PT}}$ values and their significance to determine whether populations were genetically differentiated from each other (Tables 2 and 3). The $\Phi_{\mathrm{PT}}$ values were not significantly different from 0 for populations collected from azoxystrobin- and propiconazole-treated fruit in $2013(P=0.445)$ or $2014(P=0.391)$. If mutagenesis were occurring, we would expect to see differences in these two populations in 2013 or 2014. Values for all other populations are included in Tables 2 and 3 for comparison.

$\mathrm{I}_{\mathrm{A}}$ is a measure of linkage disequilibrium and can be used as an indicator of sexual out-crossing. Values not significantly different 
from zero indicate that loci are not linked and are typically generated in a population undergoing sexual recombination. In these populations, all $\mathrm{I}_{\mathrm{A}}$ values were not significantly different from zero, with $P$ values much greater than the $\alpha=0.05$ level of significance, except for the control blossom population from $2013(P=$ $0.036)$ and the control fruit population from $2014(P=0.019)$ (Table 1).

Identification of matching pairs using gene-sequence variability. Although data are lacking, it is reasonable to assume that flowers in spring may be infected by more than one isolate and the resulting canker may be formed by an isolate mixture. For this analysis, it was critical that each isolate collected from a canker be the same as the isolate collected from the blossom. Therefore, the mrrl, DHFR, and MFCYPO1 genes were sequenced (Dowling 2015). We identified differences between $72 \%$ of the 110 canker and blossom isolate pairs but only pairs with identical $m r r l+D H F R+$ MFCYP01 gene sequences (matching pairs) were used for subsequent SSR analysis to detect potential genetic changes due to field exposure of fungicides. The $m r r l+D H F R+M F C Y P O 1$ sequence analysis identified eight pairs from each of the three field treatments at the Musser Farm that not only were matching pairs but also the majority were unique in their nucleotide sequence between pairs. In two matching pairs from the control block, all four isolates had identical nucleotide sequences. All three matching pairs identified in the control and in the azoxystrobin populations at the UGA Horticulture Research Farm were unique.

Comparison of SSR loci and Mftc1 Southern blots in matching pairs. The eight matching pairs for each of the three treatments from the Musser Farm and three matching pairs from each of the two treatments at the UGA Horticulture Research Farm were analyzed for their SSR profiles. Though two pairs were identical to each other using the three gene regions, all pairs from both Musser and UGA had unique profiles at the SSR loci. Canker and blossom isolates within each matching pair also had unique SSR profiles. (Table 4).

Southern blot $M f t c 1$ profiles of matching pairs from blossoms and cankers of each treatment block at Musser Farm were also compared. No differences between $M f t c l$ profiles were observed for any of the seven azoxystrobin-treated pairs (Fig. 4). Changes were observed in one of six and one of four Mftcl profiles of propiconazole-treated isolates and control isolates, respectively.

\section{DISCUSSION}

The purpose of this study was to investigate, on the population and individual isolate level, whether frequent and consecutive field exposure of M. fructicola to azoxystrobin could accelerate genetic changes. In this study, no changes were observed between treatments with regard to SSR-based population diversity and with regard to differences at SSR loci between isolates from the same infection site. These results do not support the hypothesis that repeated field applications of azoxystrobin may increase genetic diversity under field conditions within a single season. They are also in contrast to our earlier study that showed fungicide-induced SSR instability and transposon movement in vitro following 12 weeks of continuous exposure of M. fructicola to the QoI fungicide azoxystrobin (Chen et al. 2015; Schnabel et al. 2014). Both studies used the same SSR markers and the same transposon for
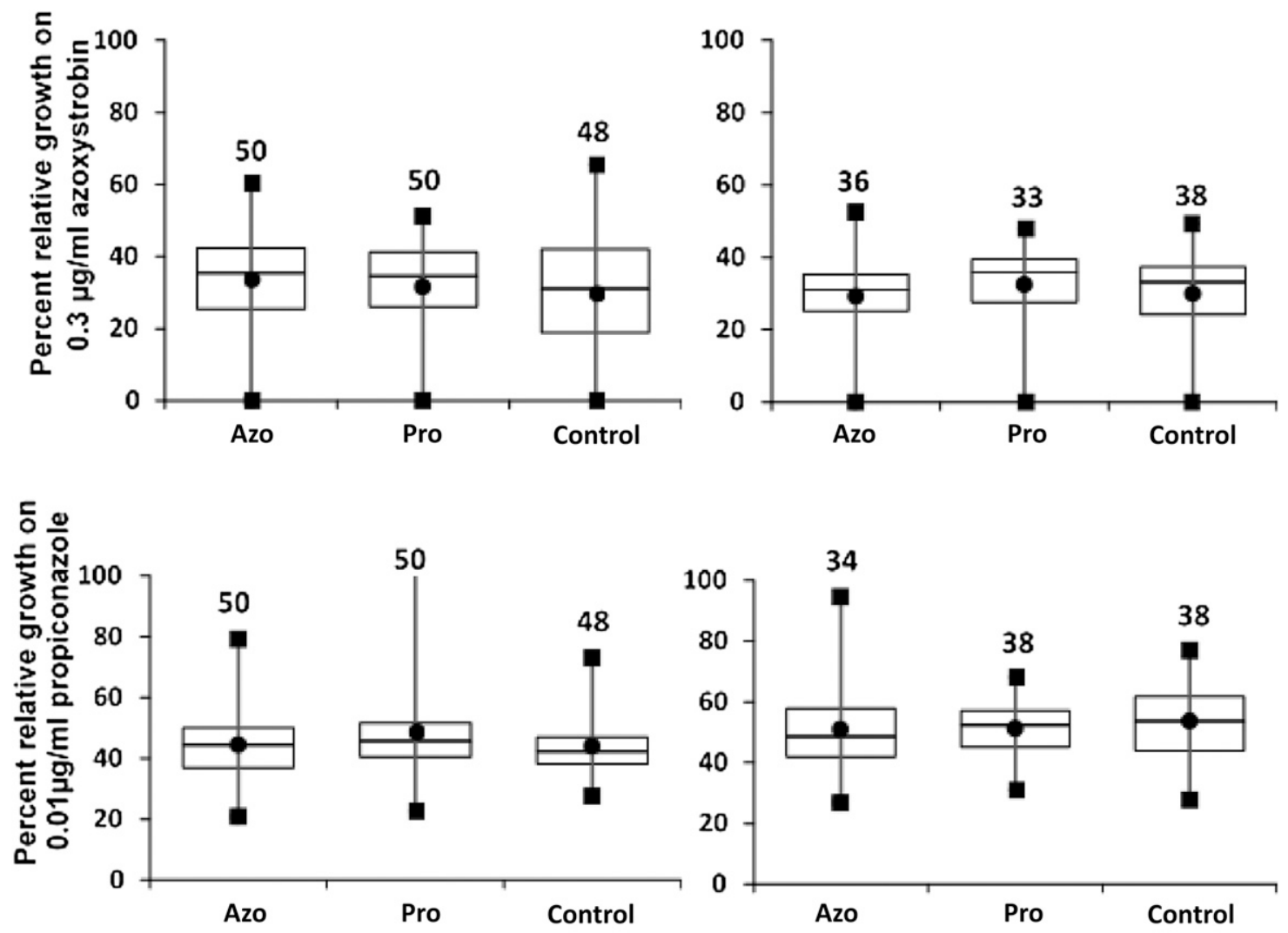

Field treatment 2013

Field treatment 2014

\section{- Min, Max • Mean}

Fig. 2. Relative mycelial growth of Monilinia fructicola isolates on azoxystrobin $(0.3 \mu \mathrm{g} / \mathrm{ml})$ and propiconazole $(0.01 \mu \mathrm{g} / \mathrm{ml})$, where isolates were obtained from one of three field treatments in 2013 and 2014: no-fungicide control, consecutive applications of half-label rate azoxystrobin (azo), or consecutive applications of half-label rate propiconazole (pro). The number of isolates analyzed is given above each box and whisker plot. 
consistency. In the in vitro study, 10 of the 13 SSR loci mutated in response to azoxystrobin exposure, and movement of the transposon $M f t c l$ was observed in response to azoxystrobin exposure for three isolates tested (Chen et al. 2015).

Mutational changes in SSR loci in response to azoxystrobin exposure was assumed to be a consequence of the sensitivity of SSR loci and associated mismatch repair (MMR) to oxidative stress. Most mutational events occurring in SSR regions are caused by polymerase slippage but are corrected by the MMR system (Schlötterer and Tautz 1992; Umar et al. 2004). MMR accuracy may be affected by ROS generated by QoI fungicides such as azoxystrobin (Fernandez-Ortuno et al. 2008; Turrens and Boveris 1980). Even small doses of ROS can completely disable several key complexes involved in MMR, and the number of retained mutations resulting from polymerase slippage increases dramatically in response to oxidative stress (Evans and Cooke 2004; Jackson and Loeb 2000; Jackson et al. 1998). The discrepancy between the in vitro study and the field study may be due to the differing levels of experimental fungicide exposure. Exposure in vitro was continuous and dose maximized, whereas exposure to field application was frequent but brief, variable, and potentially nonexistent due to fungicide degradation. Also, only mycelium and spores on blossoms

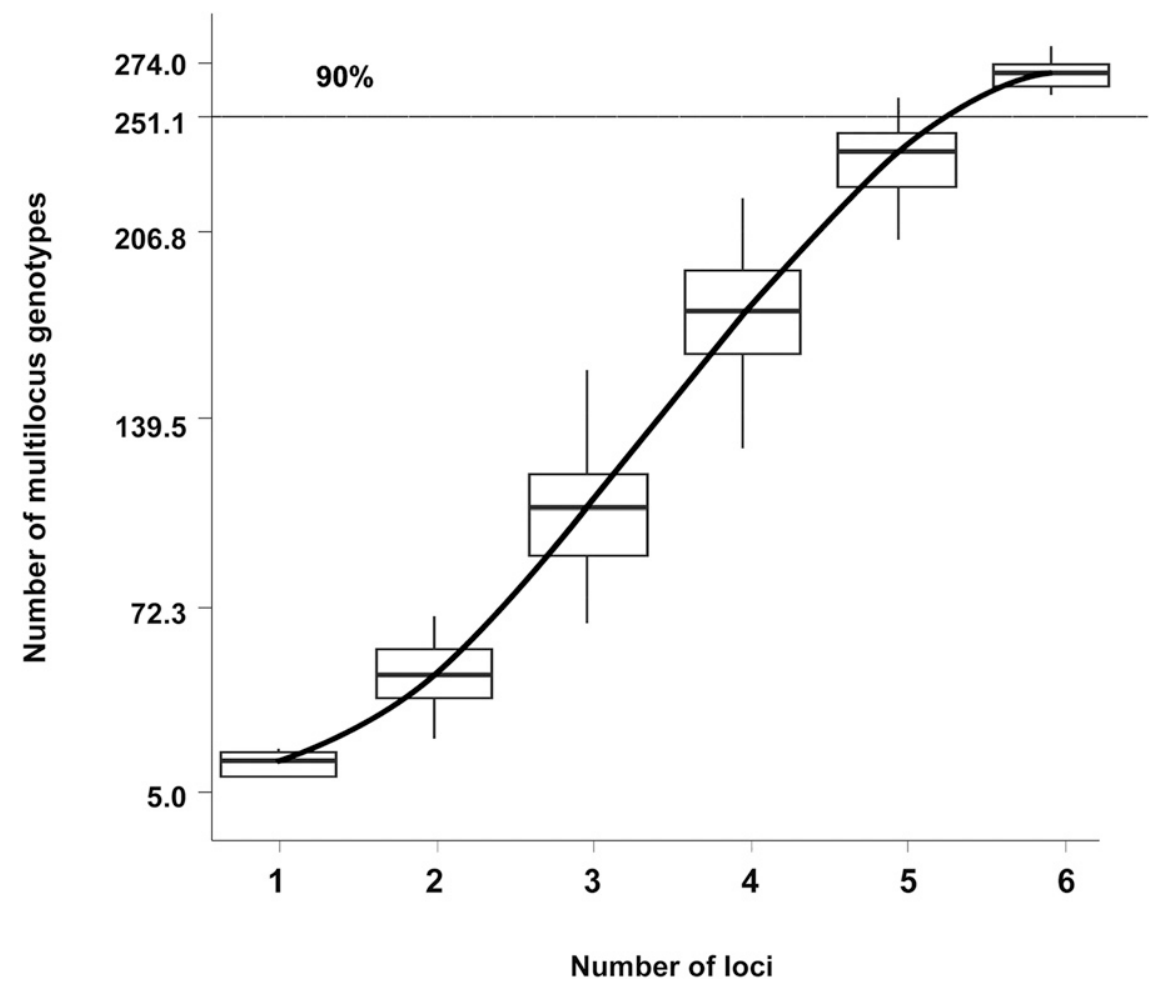

Fig. 3. Multilocus genotypes resolved with increasing number of simple-sequence repeat loci sampled among a population of 388 Monilinia fructicola isolates collected in 2013 and 2014 from blighted blossoms and symptomatic fruit.

TABLE 1. Comparison of population diversity measurements based on population variation at seven simple-sequence repeat loci of fruit and blossom populations collected in 2013 and 2014 ${ }^{a}$

\begin{tabular}{|c|c|c|c|c|c|c|c|}
\hline Year, symptom, field treatment & $N^{\mathrm{b}}$ & $\begin{array}{c}\text { Alleles } \\
\text { per locus }\end{array}$ & $\begin{array}{l}\text { Effective alleles } \\
\text { per locus }{ }^{\mathrm{c}}\end{array}$ & Private alleles ${ }^{\mathrm{b}}$ & Haploid gene diversity $(u h)^{\mathrm{c}}$ & Unique MLG $(\%)^{\mathrm{b}}$ & $\mathrm{I}_{\mathrm{A}}^{\mathrm{c}}$ \\
\hline \multicolumn{8}{|l|}{2013} \\
\hline \multicolumn{8}{|l|}{ Blighted blossom } \\
\hline Propiconazole & 25 & 4.6 & 3.0 & 2 & 0.64 & 100 & -0.067 \\
\hline Control & 25 & 5.6 & 3.9 & 5 & 0.76 & 96 & $0.134 *$ \\
\hline \multicolumn{8}{|l|}{ Fruit rot } \\
\hline Azoxystrobin & 25 & 5.7 & 3.7 & 6 & 0.71 & 88 & 0.011 \\
\hline \multicolumn{8}{|l|}{2014} \\
\hline \multicolumn{8}{|l|}{ Blighted blossom } \\
\hline Azoxystrobin & 25 & 5.7 & 2.7 & 8 & 0.61 & 96 & 0.097 \\
\hline Propiconazole & 25 & 5.9 & 4.0 & 10 & 0.73 & 100 & 0.050 \\
\hline Control & 25 & 4.7 & 2.7 & 2 & 0.61 & 96 & -0.095 \\
\hline \multicolumn{8}{|l|}{ Fruit rot } \\
\hline Azoxystrobin & 25 & 5.4 & 3.3 & 4 & 0.68 & 100 & 0.107 \\
\hline
\end{tabular}

a $N=$ number of isolates in each population, $\mathrm{MLG}=$ multilocus genotypes, and $\mathrm{I}_{\mathrm{A}}=$ index of association. Asterisk denotes significant $\mathrm{I}_{\mathrm{A}}$ value compared with 999 randomizations.

b Non-clone-corrected data.

c Clone-corrected data. 
or fruit surfaces were directly exposed to high fungicide doses, whereas mycelium in plant tissue may not have been exposed at all due to limited systemic movement of both fungicides in plant tissues, especially woody tissue (Anesiadis et al. 2003; Bartlett et al. 2002; Burnett et al. 2010; Sudisha et al. 2005). It is also possible that antioxidants produced in field conditions might quench ROS. One study indicated that peach fruit can respond to $M$. fructicola infection by producing caffeic acid, a phenolic compound that appears to induce upregulation of an antioxidant within the fungus (Lee and Bostock 2007). Similar phenolic-induced quenching of ROS has been documented in the rice-blast fungus Magnaporthe grisea and is believed to limit alternative oxidase activity of the fungus in vivo (Wood and Hollomon 2003). In Monilinia fructicola, alternative oxidase is active in vitro but not in vivo, indicating that similar ROS quenching may be occurring.

Polymorphism at each of the seven SSR loci used in this study allowed differentiation of genotypes of $M$. fructicola within treatment populations. These loci provided sufficient resolution of isolates, as determined by the genotype accumulation curve that began to plateau at 6 loci. Comparisons of haploid genetic diversity, number of alleles, percent unique MLG, and $\Phi_{\mathrm{PT}}$ between treatments indicated that increased mutagenesis did not occur at the population level at the loci examined in this study following field exposure to either propiconazole or azoxystrobin. Consistent with our population analysis, comparison of blossom and canker pairs revealed no changes in SSR loci or transposon profile in isolates from fungicide treatments compared with those from the control treatment.

In order to ensure that isolates originated from the same clonal population, it was imperative to use less mutable regions than SSR loci for initial comparison of isolates. The variable gene regions

TABLE 2. Pairwise comparisons of Monilinia fructicola clone-corrected blossom and fruit populations from $2013^{\mathrm{a}}$

\begin{tabular}{lcccccc}
\hline & \multicolumn{5}{c}{ Population } \\
\cline { 2 - 7 } Population & AzoB13 & ProB13 & ConB13 & AzoF13 & ProF13 & ConF13 \\
\hline AzoB13 & $\ldots$ & $\ldots$ & $\ldots$ & $\ldots$ & $\ldots$ & $\ldots$ \\
ProB13 & $0.021 *$ & $\ldots$ & $\ldots$ & $\ldots$ & $\ldots$ & $\ldots$ \\
ConB13 & 0.001 & 0.006 & $\ldots$ & $\ldots$ & $\ldots$ & $\ldots$ \\
AzoF13 & 0.000 & 0.015 & 0.017 & $\ldots$ & $\ldots$ & $\ldots$ \\
ProF13 & 0.009 & 0.000 & 0.009 & 0.000 & $\ldots$ & $\ldots$ \\
ConF13 & 0.000 & 0.006 & 0.011 & 0.003 & 0.009 & $\ldots$ \\
\hline a All $\Phi_{\text {PT values below the diagonal were calculated from clone-corrected data }}$ \\
using analysis of molecular variance with 999 randomizations. Azo, Pro, and \\
Con stand for azoxystrobin, propiconazole, and control treatments, re- \\
spectively. The next letter indicates whether the isolate was collected from \\
blossom (B) or fruit (F), and the following numbers indicate that the year of \\
collection (2013). An asterisk indicates a $\Phi_{\text {PT value significantly different }}$ \\
from zero.
\end{tabular}

TABLE 3. Pairwise comparisons of Monilinia fructicola clone-corrected blossom and fruit populations from 2014 ${ }^{\mathrm{a}}$

\begin{tabular}{lcccccc}
\hline & \multicolumn{6}{c}{ Population } \\
\cline { 2 - 7 } Population & AzoB14 & ProB14 & ConB14 & AzoF14 & ProF14 & ConF14 \\
\hline AzoB14 & $\ldots$ & $\ldots$ & $\ldots$ & $\ldots$ & $\ldots$ & $\ldots$ \\
ProB14 & $0.027^{*}$ & $\ldots$ & $\ldots$ & $\ldots$ & $\ldots$ & $\ldots$ \\
ConB14 & 0.006 & $0.029^{*}$ & $\ldots$ & $\ldots$ & $\ldots$ & $\ldots$ \\
AzoF14 & $0.025^{*}$ & $0.022^{*}$ & $0.034^{*}$ & $\ldots$ & $\ldots$ & $\ldots$ \\
ProF14 & $0.025^{*}$ & $0.017^{*}$ & $0.034^{*}$ & 0.002 & $\ldots$ & $\ldots$ \\
ConF14 & $0.138^{*}$ & $0.082^{*}$ & $0.154^{*}$ & $0.119^{*}$ & $0.106^{*}$ & $\ldots$ \\
\hline
\end{tabular}

a All $\Phi_{\mathrm{PT}}$ values below the diagonal were calculated from clone-corrected data using analysis of molecular variance with 999 randomizations. Azo, Pro, and Con stand for azoxystrobin, propiconazole, and control treatments, respectively. The next letter indicates whether the isolate was collected from blossom (B) or fruit $(\mathrm{F})$, and the following numbers indicate that the year of collection (2014). An asterisk indicates a $\Phi_{\mathrm{PT}}$ value significantly different from zero. $m r r 1, D H F R$, and MFCYP01, used for fingerprinting, were shown to be less mutable than SSR regions and allowed us to distinguish isolates collected from cankers and blossoms at the same infection site (Dowling 2015). This ability to differentiate individual isolates from each other not only allowed us to match pairs for mutagenesis analysis but also revealed some insights into the epidemiology of $M$. fructicola. We occasionally found multiple genotypes colonizing a single blossom, indicating that multiple infections can lead to blossom blight, agreeing with former understanding of M. fructicola life cycle. Studies about blossom infections are rare but it is assumed that blossoms may be infected by more than one spore, and that these spores may infect any flower tissue, though no recent studies appear to have researched this phenomenon (Byrde and Willetts 1977; Holb 2008). Whether mutagenized isolates would have a fitness or competitive disadvantage leading to a disappearance because multiple isolates infected a single blossom was not investigated in this study. Whether a single or multiple genotypes may eventually cause twig canker was not investigated in this study.

The high genotypic diversity and the low $\mathrm{I}_{\mathrm{A}}$ values of populations documented in this study support the hypothesis that sexually produced ascospores are the primary inoculum source for blossom

TABLE 4. Comparison of blossom (B) and canker (C) isolates at seven simplesequence repeat (SSR) loci: SED, SEF, SEI, SEL, SEN, SEP, and SEQ ${ }^{a}$

\begin{tabular}{|c|c|c|c|c|c|c|c|c|}
\hline \multirow[b]{2}{*}{ Treatment } & \multirow[b]{2}{*}{ Isolate pair ${ }^{\mathrm{b}}$} & \multicolumn{7}{|c|}{ SSR loci } \\
\hline & & SED & SEF & SEI & SEL & SEN & SEP & SEQ \\
\hline \multirow[t]{8}{*}{ Azoxystrobin } & 3.1.6 B,C & 131 & 126 & 110 & 137 & 227 & 250 & 136 \\
\hline & $3.1 .8 \mathrm{~B}, \mathrm{C}$ & 145 & 131 & 114 & 147 & 227 & 254 & 134 \\
\hline & 3.2.17 B,C & 131 & 117 & 114 & 137 & 231 & 247 & 138 \\
\hline & 3.2 .7 B,C & 141 & 131 & 114 & 143 & 231 & 247 & 134 \\
\hline & $3.2 .8 \mathrm{~B}, \mathrm{C}$ & 131 & 117 & 104 & 143 & 227 & 254 & 132 \\
\hline & 3.4.1 B,C & 131 & 131 & 114 & 147 & 223 & 247 & 132 \\
\hline & 4.1.4 B,C & 135 & 144 & 114 & 137 & 231 & 254 & 130 \\
\hline & 4.5.11 B,C & 131 & 126 & 104 & 137 & 231 & 231 & 138 \\
\hline \multirow[t]{9}{*}{ Propiconazole } & 9.2 .18 B,C & 131 & 117 & 114 & 143 & 231 & 254 & 134 \\
\hline & 9.5.3 B,C & 131 & 131 & 114 & 137 & 223 & 254 & 136 \\
\hline & 9.5.6 B,C & 131 & 144 & 104 & 143 & 235 & 231 & 136 \\
\hline & 9.5.7 B,C & 131 & 144 & 114 & 137 & 231 & 254 & 138 \\
\hline & 10.1.8 B,C & 131 & 139 & 114 & 137 & 227 & 265 & 134 \\
\hline & 10.2.2 B,C & 145 & 117 & 114 & 147 & 223 & 254 & 134 \\
\hline & 10.3.2 B,C & 145 & 117 & 110 & 147 & 227 & 254 & 132 \\
\hline & 10.5.17 B,C & 135 & 123 & 114 & 147 & 227 & 257 & 138 \\
\hline & 10.5.7 B,C & 127 & 126 & 114 & 143 & 227 & 254 & 140 \\
\hline \multirow{9}{*}{$\begin{array}{l}\text { Unsprayed } \\
\text { control }\end{array}$} & & & & & & & & \\
\hline & 6.1.8 B,C & 141 & 139 & 114 & 147 & 223 & 254 & 138 \\
\hline & $6.2 .13 \mathrm{~B}, \mathrm{C}$ & 133 & 135 & 114 & 143 & 231 & 254 & 146 \\
\hline & 6.3.18 B,C & 131 & 117 & 114 & 137 & 227 & 254 & 140 \\
\hline & 6.4.4 B,C & 141 & 123 & 102 & 143 & 231 & 231 & 134 \\
\hline & 7.1.1 B,C & 131 & 117 & 110 & 143 & 227 & 254 & 138 \\
\hline & 7.2.17 B,C & 131 & 117 & 98 & 137 & 227 & 254 & 138 \\
\hline & 7.3.12 B,C & 131 & 117 & 114 & 143 & 235 & 250 & 140 \\
\hline & 7.5.4 B,C & 131 & 127 & 104 & 137 & 227 & 250 & 138 \\
\hline \multicolumn{9}{|l|}{ UGA } \\
\hline \multirow[t]{3}{*}{ azoxystrobin $^{\mathrm{c}}$} & Azo82 B,C & 127 & 149 & 110 & 143 & 227 & 254 & 125 \\
\hline & Azo13 B,C & 117 & 106 & 114 & 137 & 223 & 254 & 130 \\
\hline & Azo93 B,C & 127 & 127 & 114 & 137 & 227 & 254 & 138 \\
\hline \multirow[t]{3}{*}{ 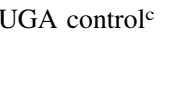 } & Con176 B,C & 141 & 135 & 117 & 143 & 223 & 254 & 136 \\
\hline & Con66 B,C & 106 & 131 & 98 & 136 & 231 & 254 & 134 \\
\hline & Con91 B,C & 106 & 126 & 114 & 143 & 227 & 250 & 134 \\
\hline
\end{tabular}

a Each number below the locus name represents a fragment size for an isolate at each locus. All of the blossoms and cankers in isolate pairs shown below matched at all SSR loci.

b Isolate pair names (i.e., 3.1.6) are based on the location where they were obtained, where the first number represents the collection row, the second number the tree collected from, and the third number the isolate number. The designation $\mathrm{B}, \mathrm{C}$ in a single row represents isolates from a matching pair, or a canker and blossom from the same infection site with matching fragment sizes at all SSR loci.

c University of Georgia (UGA) azoxystrobin and UGA control isolates were collected from orchard blocks at the UGA Horticulture Research Farm treated with azoxystrobin and untreated, respectively. All other isolates are from the Musser Fruit Research Farm. 
infections. Though the control blossoms from 2013 and the control fruit of 2014 had $\mathrm{I}_{\mathrm{A}}$ values significantly different from zero, the populations around them did not, indicating that there is some sexual reproduction occurring in the field. These indications of sexual reproduction were unexpected, considering that, in both experimental years, no apothecia were detected during bloom on fruit mummies on the orchard floor or in nearby peach dump sites located between brush piles at the edge of woods. In a former study, however, apothecia were detected on fallen mummies in orchards in the southeastern United States where mummies were not removed to dump sites as well as under wild plum trees just outside the orchard (Landgraf and Zehr 1982). Parasexual recombination could be another cause of the high diversity observed in this study but parasexuality in $M$. fructicola has not yet been clearly described.

Although disease incidence significantly decreased in fungicide treatments compared with the control, the number of MLG did not decrease significantly. This result contradicts the initial experimental hypothesis that fungicide treatments would select for lesssensitive genotypes and, thus, cause a reduction of genotypes. It is possible that the resolution of our technique to distinguish genotypes was not sufficient to detect a reduction in genotypes. It appears, however, that fungicide treatments did not reduce genetic diversity. The implications of this result are interesting because they appear to agree with the recently published models that support using low-dose applications as a method for resistance management (Ishii and Hollomon 2015). This study utilized a half-label rate dose; therefore, it can only support and not confirm benefits of using a low dose for resistance management.
Assessment of phenotypic characteristics of treatment populations revealed no changes in population responses to fungicide sensitivity. Sensitivity of fungicide-exposed field populations to azoxystrobin and propiconazole in vitro was not different compared with the control, indicating that little or no selection for resistance occurred during the season. This is consistent with our genotypic data described above and supports the argument that fungicide treatments did not reduce the population by killing off the most sensitive individuals but, rather, prevented existing genotypes from progressing. No changes in sensitivity to cyprodinil and iprodione were detected in vitro. Both fungicides belong to chemical classes unrelated to those used for field applications. This lack of change indicates that no resistant genotypes had randomly arisen in response to increased mutagenesis. Again, this is consistent with the overall conclusion of this study that a half-label rate of azoxystrobin does not accelerate mutagenesis under field conditions but stands in contrast to findings in other systems where pathogen populations subjected to site-specific fungicides were predisposed to developing resistance to unrelated fungicides (Köller and Wilcox 2001).

In conclusion, genotypic and phenotypic analysis of $M$. fructicola populations that were exposed to frequent and consecutive applications of azoxystrobin and propiconazole in the field did not provide evidence of increased mutagenesis. Analysis of individual isolates collected before and after consecutive fungicide applications concurred with population data, also indicating that no mutagenesis took place. Additional comparison at the genome level of isolate pairs collected before and after exposure would be necessary to

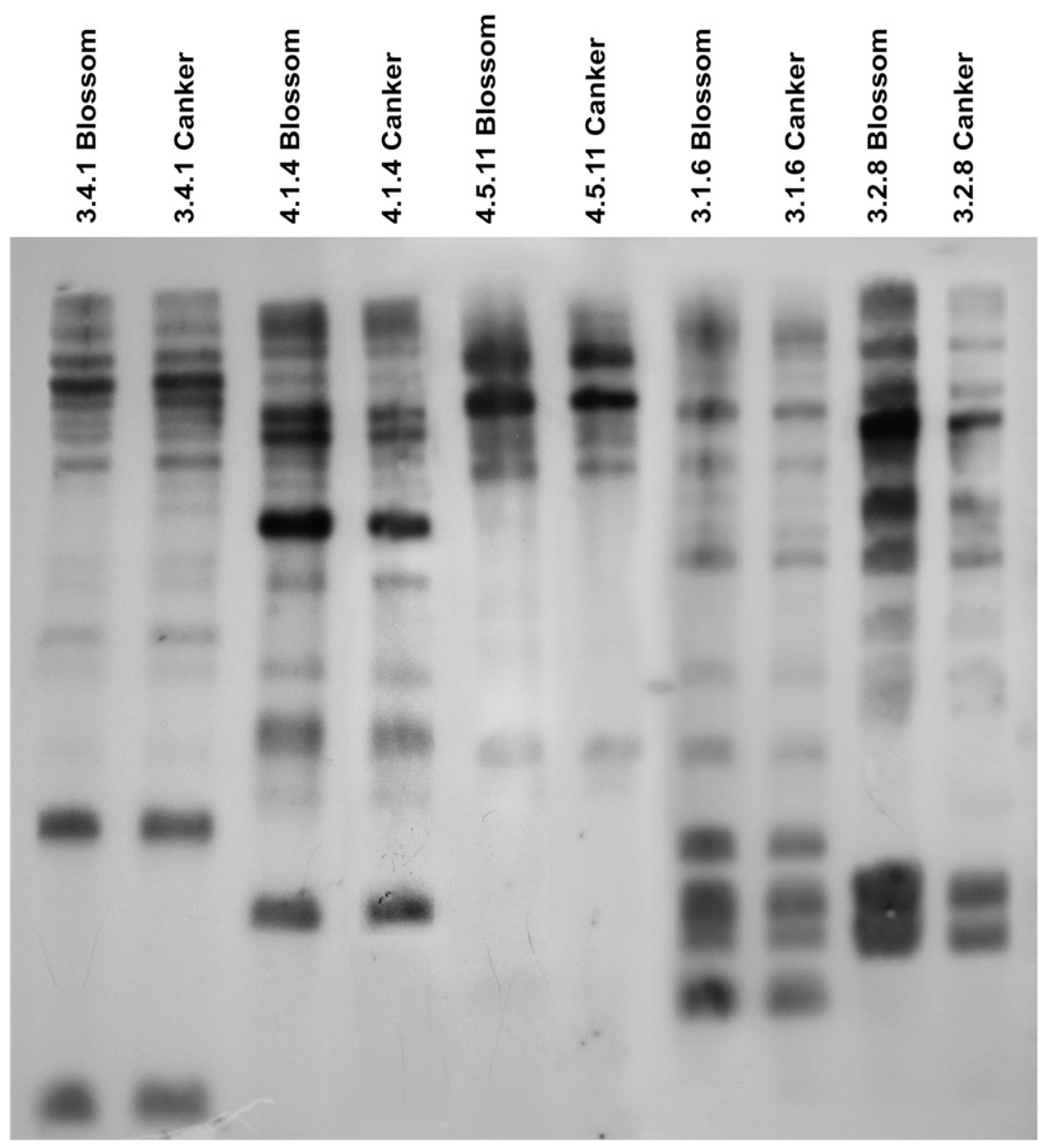

Fig. 4. Southern blot showing Mftcl transposon profiles of complementary canker and blighted blossom pairs from azoxystrobin-treated trees. 
conclusively show that lack of fungicide-induced mutagenesis occurred in these isolates.

\section{ACKNOWLEDGMENTS}

This project was supported by Technical Contribution Number 6464 of the Clemson University Experiment Station and by the United States Department of Agriculture National Institute of Food and Agriculture, under project number SC-1700501 and 2014-51181-22377. We thank J. Hopkins, S. Hudson, R. McNeill, and the rest of the staff at the Musser and UGA Horticulture Research Farms for assistance in fungicide applications and orchard maintenance; and H. Ishii, M.-J. Hu, F. Fei, S. Li, S. Xi, N. Yuan, M. Becker, A. Grabke, and J.-H. Yang for their help with isolate collection.

\section{LITERATURE CITED}

Ames, G. K. 2012. Peaches: Organic and Low-Spray Production. T. Mumma, ed. National Center for Appropriate Technology, Butte, MT.

Anesiadis T., Karaoglanidis G. S., and Tzavella-Klonari K. 2003. Protective, curative and eradicant activity of the strobilurin fungicide azoxystrobin against Cercospora beticola and Erysiphe betae. J. Phytopathol. 151: 647-651.

Bartlett, D. W., Clough, J. M., Godwin, J. R., Hall, A. A., Hamer, M., and Parr-Dobrzanski, B. 2002. The strobilurin fungicides. Pest Manage. Sci. 58: 649-662.

Beckerman J. 2008. Disease Management Strategies: Fungicide Rotations for Nursery, Greenhouse, and Landscape Professionals. Purdue University Extension Publication BP-071-W

Burnett, A. L., Lalancette, N., and McFarland, K. A. 2010. Effect of QoI fungicides on colonization and sporulation of Monilinia fructicola on peach fruit and blossom blight cankers. Plant Dis. 94:1000-1008.

Byrde, R. J. W., and Willetts, H. J. 1977. The Brown Rot Fungi of Fruit. Their Biology and Control, 1st ed. Pergamon Press, Elmsford, NY.

Chadha S., and Sharma M. 2014. Transposable elements as stress adaptive capacitors induce genomic instability in fungal pathogen Magnaporthe oryzae. PLoS One 9:e94415.

Chen, F., Everhart, S. E., Bryson, P. K., Luo, C., Song, X., Liu, X., and Schnabel, G. 2015. Fungicide-induced transposon movement in Monilinia fructicola. Fungal Genet. Biol. 85:38-44.

Chi, M., Park, S., and Lee, Y. 2009. A quick and safe method for fungal DNA extraction. Plant Pathol. J. 25:108-111.

Dowling, M. 2015. Influence of repeated field applications of azoxystrobin on population diversity of Monilinia fructicola. Dissertation, Clemson University, Clemson, SC.

Evans, M. D., and Cooke, M. S. 2004. Factors contributing to the outcome of oxidative damage to nucleic acids. BioEssays 26:533-542.

Everhart, S. E., Askew, A., Seymour, L., Glenn, T. C., and Scherm, H. 2012. Spatial patterns of brown rot epidemics and development of microsatellite markers for analyzing fine-scale genetic structure of Monilinia fructicola populations within peach tree canopies. Online publication. Plant Health Prog. doi:10.1094/PHP-2012-0723-04-RS

Fernandez-Ortuno, D., Tores, J. A., de Vicente, A., and Perez-Garcia, A. 2008. Mechanisms of resistance to QoI fungicides in phytopathogenic fungi. Int. Microbiol. 11:1-9.

GE Healthcare. 2006a. Amersham Gene Images AlkPhos Direct Labelling and Detection System, RPN3680PC Rev B ed. GE Healthcare UK Limited, Amersham Place Little Chalfont, Buckinghamshire, UK.

GE Healthcare. 2006b. 4.2 Solutions. Pages 9-10 in: Amersham Hybond-N+ Product Booklet. GE Healthcare UK Limited, Amersham Place Little Chalfont, Buckinghamshire, UK.

GE Healthcare. 2006c. 5.1 Protocol for Capillary Blotting. Pages 13-15 in: Amersham Hybond-N+ Product Booklet. GE Healthcare UK Limited, Amersham Place Little Chalfont, Buckinghamshire, UK.

Georg R. C., Stefani R. M., and Gomes S. L. 2009. Environmental stresses inhibit splicing in the aquatic fungus Blastocladiella emersonii. BMC Microbiol. 9:231

Gisi U., Chin K. M., Knapova G., Küng Färber R., Mohr U., Parisi S., Sierotzki H., and Steinfeld U. 2000. Recent developments in elucidating modes of resistance to phenylamide, DMI and strobilurin fungicides. Crop Prot. 19:863-872.

Grimmer, M. K., van den Bosch, F., Powers, S. J., and Paveley, N. D. 2015. Fungicide resistance risk assessment based on traits associated with the rate of pathogen evolution. Pest Manage. Sci. 71:207-215.

Holb, I. 2008. Brown rot blossom blight of pome and stone fruits: Symptom, disease cycle, host resistance, and biological control. Int. J. Hortic. Sci. 14:15-21.

Honey, E. E. 1936. North American species of Monilinia. I. Occurrence, grouping, and life- histories. Am. J. Bot. 23:100-106.
Horton, D., Brannen, P., Bellinger, B., Lockwood, D., and Ritchie, D. 2014. 2014 Southeastern Peach, Nectarine and Plum Pest Management and Culture Guide. Spray Guide. University of Georgia Cooperative Extension, University of Georgia, Athens, GA.

Ishii, H., and Hollomon, D. W., eds. 2015. Fungicide Resistance in Plant Pathogens: Principles and a Guide to Practical Management. Springer Japan, Japan.

Jackson, A. L., Chen, R., and Loeb, L. A. 1998. Induction of microsatellite instability by oxidative DNA damage. Proc. Natl. Acad. Sci. USA 95: $12468-12473$

Jackson, A. L., and Loeb, L. A. 2000. Microsatellite Instability Induced by Hydrogen Peroxide in Escherichia coli. Mutat. Res. Fundam. Mol. Mech. Mutagen. 447:187-198

Kamvar, Z. N., Tabima, J. F., and Grünwald, N. J. 2014. Poppr: An R package for genetic analysis of populations with clonal, partially clonal, and/or sexual reproduction. PeerJ 2:e281.

Kaneko, I., and Ishii, H. 2009. Effect of azoxystrobin on activities of antioxidant enzymes and alternative oxidase in wheat head blight pathogens Fusarium graminearum and Microdochium nivale. J. Gen. Plant Pathol. 75: 388-398.

Köller, W., and Wilcox, W. F. 2001. Evidence for the predisposition of fungicide-resistant isolates of Venturia inaequalis to a preferential selection for resistance to other fungicides. Phytopathology 91:776-781.

Landgraf, F. A., and Zehr, E. I. 1982. Inoculum sources for Monilinia fructicola in South Carolina peach orchards. Phytopathology 72:185-190.

Lee, M. H., and Bostock, R. M. 2007. Fruit exocarp phenols in relation to quiescence and development of Monilinia fructicola infections in Prunus spp.: A role for cellular redox? Phytopathology 97:269-277.

Luo, C., Cox, K. D., Amiri, A., and Schnabel, G. 2008. Occurrence and detection of the DMI resistance-associated genetic element 'Mona' in Monilinia fructicola. Plant Dis. 92:1099-1103.

Luo, C., Hu, M., Jin, X., Yin, L., Bryson, P. K., and Schnabel, G. 2010. An intron in the cytochrome $b$ gene of Monilinia fructicola mitigates the risk of resistance development to QoI fungicides. Pest Manage. Sci. 66:1308-1315.

Luo, C. X., and Schnabel, G. 2008. The cytochrome P450 lanosterol 14-demethylase gene is a demethylation inhibitor fungicide resistance determinant in Monilinia fructicola field isolates from Georgia. Appl. Environ. Microbiol. 74:359-366.

Mizutani, A. 1996. A possible mechanism of control of rice blast disease by a novel alkoxyiminoacetamide fungicide, SSF126. Phytopathology 86:295-300.

Ogawa, J. M., Zehr, E. I., Bird, G. W., Ritchie, D. F., Uriu, K., and Uyemoto, J. K. 1995. Compendium of Stone Fruit Diseases. American Phytopathological Society, St. Paul, MN

Peakall, R., and Smouse, P. E. 2006. Genalex 6: Genetic analysis in Excel. Population genetic software for teaching and research. Mol. Ecol. Notes 6: 288-295.

Roberts, J. W., and Dunegan, J. C. 1932. Peach Brown Rot. United States Department of Agriculture, Washington, D.C.

Schlötterer, C., and Tautz, D. 1992. Slippage synthesis of simple sequence DNA. Nucleic Acids Res. 20:211-215.

Schnabel, G., Chen, F., Everhart, S. E., Bridges, W. C., and Liu, X. 2014. Studies on sensitivity reduction in solo and mixture treatments and fungicideinduced mutagenesis in Monilinia fructicola. Pages 263-268 in: Modern Fungicides and Antifungal Compounds VII: Proc. 17th Int. Reinhardsbrunn Symp. H. W. Dehne, H. B. Deising, B. Fraaije, U. Gisi, D. Hermann, A. Mehl, E. C. Oerke, P. E. Russell, G. Stammler, K. H. Kuck, and H. Lyr, eds. DPG Verlag, Braunschweig, Germany.

Sudisha, J., Amruthesh, K. N., Deepak, S. A., Shetty, N. P., Sarosh, B. R., and Shetty, H. S. 2005. Comparative efficacy of strobilurin fungicides against downy mildew disease of pearl millet. Pestic. Biochem. Physiol. 81: 188-197.

Sutton, T. B., and Clayton, C. N. 1972. Role and survival of Monilinia fructicola in blighted peach branches. Phytopathology 62:1369-1373.

Turrens, J. F., and Boveris, A. 1980. Generation of superoxide anion by the NADH dehydrogenase of bovine heart mitochondria. Biochem. J. 191: 421-427.

Umar, A., Boland, C. R., Terdiman, J. P., Syngal, S., Chapelle, A. 1., Ruschoff, J., Fishel, R., Lindor, N. M., Burgart, L. J., Hamelin, R., Hamilton, S. R., Hiatt, R. A., Jass, J., Lindblom, A., Lynch, H. T., Peltomaki, P., Ramsey, S. D., Rodriguez-Bigas, M. A., Vasen, H. F. A., Hawk, E. T., Barrett, J. C., Freedman, A. N., and Srivastava, S. 2004. Revised Bethesda guidelines for hereditary nonpolyposis colorectal cancer (Lynch syndrome) and microsatellite instability. J. Natl. Cancer Inst. 96:261-268.

Wood, P. M., and Hollomon, D. W. 2003. A critical evaluation of the role of alternative oxidase in the performance of strobilurin and related fungicides acting at the Qo site of Complex III. Pest Manage. Sci. 59:499-511.

Zhong, Y. F., Zhang, Y. W., Chen, X. Y., Luo, Y., and Guo, L. Y. 2008. Overwintering of Monilinia fructicola in Stone Fruit Orchards in Northern China. J. Phytopathol. 156:229-235. 